\title{
Cleaner Fuel Production via Co-Processing of Vacuum Gas Oil with Rapeseed Oil Using a Novel NiW/Acid-Modified Phonolite Catalyst
}

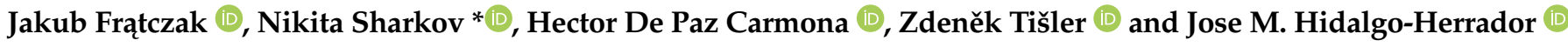

check for updates

Citation: Frątczak, J.; Sharkov, N.; De Paz Carmona, H.; Tišler, Z.; Hidalgo-Herrador, J.M. Cleaner Fuel Production via Co-Processing of Vacuum Gas Oil with Rapeseed Oil Using a Novel NiW/Acid-Modified Phonolite Catalyst. Energies 2021, 14 , 8497. https://doi.org/10.3390/ en14248497

Academic Editor: Poul Alberg Østergaard

Received: 29 October 2021 Accepted: 9 December 2021 Published: 16 December 2021

Publisher's Note: MDPI stays neutral with regard to jurisdictional claims in published maps and institutional affiliations.

Copyright: (c) 2021 by the authors. Licensee MDPI, Basel, Switzerland. This article is an open access article distributed under the terms and conditions of the Creative Commons Attribution (CC BY) license (https:// creativecommons.org/licenses/by/ $4.0 /)$.
ORLEN UniCRE, a.s., Revoluční 1521/84, 40001 Ústí nad Labem, Czech Republic; jakub.fratczak@unicre.cz (J.F.); Hector.Carmona@unicre.cz (H.D.P.C.); Zdenek.Tisler@unicre.cz (Z.T.); jose.hidalgo@unicre.cz (J.M.H.-H.)

* Correspondence: nikita.sharkov@unicre.cz

\begin{abstract}
Clean biofuels are a helpful tool to comply with strict emission standards. The co-processing approach seems to be a compromise solution, allowing the processing of partially bio-based feedstock by utilizing existing units, overcoming the need for high investment in new infrastructures. We performed a model co-processing experiment using vacuum gas oil (VGO) mixed with different contents $(0 \%, 30 \%, 50 \%, 70 \%, 90 \%$, and $100 \%)$ of rapeseed oil (RSO), utilizing a nickel-tungsten sulfide catalyst supported on acid-modified phonolite. The experiments were performed using a fixed-bed flow reactor at $420{ }^{\circ} \mathrm{C}$, a hydrogen pressure of $18 \mathrm{MPa}$, and a weight hourly space velocity (WHSV) of $3 \mathrm{~h}^{-1}$. Surprisingly, the catalyst stayed active despite rising oxygen levels in the feedstock. In the liquid products, the raw diesel $\left(180-360^{\circ} \mathrm{C}\right)$ and jet fuel $\left(120-290^{\circ} \mathrm{C}\right)$ fraction concentrations increased together with increasing RSO share in the feedstock. The sulfur content was lower than 200 ppm for all the products collected using feedstocks with an RSO share of up to $50 \%$. However, for all the products gained from the feedstock with an RSO share of $\geq 50 \%$, the sulfur level was above the threshold of $200 \mathrm{ppm}$. The catalyst shifted its functionality from hydrodesulfurization to (hydro)decarboxylation when there was a higher ratio of RSO than VGO content in the feedstock, which seems to be confirmed by gas analysis where increased $\mathrm{CO}_{2}$ content was found after the change to feedstocks containing $50 \%$ or more RSO. According to the results, NiW/acid-modified phonolite is a suitable catalyst for the processing of feedstocks with high triglyceride content.
\end{abstract}

Keywords: co-processing; acid-modified phonolite; hybrid fuels; VGO; RSO

\section{Introduction}

In the European Union (EU), road (71.7\%), aviation (13.9\%), and marine $(13.3 \%)$ transport are responsible for almost $99 \%$ of the greenhouse gas (GHG) emissions of the transportation sector [1], primarily due to their heavy utilization of fossil fuels. Thus, there is much interest in the development of "clean" fuels. One promising strategy involves the introduction of biofeedstock processing in refineries. However, traditional petroleum refineries have a well-developed infrastructure for crude oil processing and usually lack newer units able to process biofeeds. To avoid huge investment costs, the co-processing of bio-based starting materials with petroleum-derived feedstocks could offer a compromise solution [2-4] for such refineries.

The co-processing approach can help to produce a hybrid (petroleum- and bio-derived) fuel that reduces GHG emissions through biomass utilization. Because vacuum gas oil (VGO), the product from the vacuum distillation of atmospheric residue, is the most widely used feedstock for cracking processes [5], it has been used as a petroleum-derived blending component for co-processing mixtures [6]. Vegetable oils, such as rapeseed oil (RSO), are also considered good candidates for fuel production due to their high triglyceride content [7]. Several studies have investigated RSO content in co-processing feedstocks [8-10], 
and it has been reported that the use of RSO can have a positive synergistic effect when coprocessed with VGO [11]. Thus, VGO and RSO, as respective petroleum- and bio-derived fractions, appear to be suitable candidates for use in co-processing for the production of cleaner fuels.

Furthermore, research by Doronin et al. [9] showed that the yields of the target cracking products from vegetable oils do not reach the level of values obtained in the processing of vacuum gas oil, a traditional cracking feedstock. This is primarily due to the fatty acid composition of vegetable oils. The processing of vegetable oils under cracking conditions is not entirely appropriate due to the high reactivity of the primary products of thermal decomposition of the initial triglycerides of oils-C15-C18 olefins. In this regard, the interest is mainly in the joint cracking of raw materials of plant and petroleum origin [12-14]. The high reactivity of the primary products of thermal decomposition of the starting triglycerides of vegetable oils can adversely affect both the quantity and quality of cracking products. For this reason, it is advisable to carry out co-processing of vacuum gas oil and vegetable oil.

In addition to the selection of raw materials for the joint conversion of vacuum gas oil with vegetable oil under cracking conditions, the choice of a catalyst remains an important aspect. The above-mentioned studies used catalytic hydrocracking, a process that aims to reduce the boiling point of the feedstock, for co-processing. The most commonly used catalysts for hydro-processing are based on Co-Mo [15] or Ni-Mo [16] sulfides. However, these metal complexes favor the hydrodeoxygenation pathway for the removal of oxygen, meaning that $\mathrm{O}_{2}$ and $\mathrm{H}_{2}$ are converted into water molecules during the process. Due to the undesired hydrogen consumption related to water formation, other metals have been studied, such as nickel-tungsten (NiW). In particular, it was reported that NiW catalysts mostly favor the decarbonylation and decarboxylation pathways for oxygen removal, thereby consuming far less hydrogen compared with hydrodeoxygenation [17]. Thus, NiW catalysts appear to be more suitable for feedstocks with higher oxygen content and, thus, an increased bio-derived fraction.

A wide variety of support materials (zeolites, alumina, silica-alumina, etc.) have been used in the synthesis of NiW catalysts [18-20]. Nevertheless, other potential support materials remain to be explored, one of which is phonolite. As an extrusive volcanic rock, it is primarily composed of alkali feldspar and, being widespread in nature, is easily accessible and cheap [21]. In its default form, phonolite is a solid non-porous material. However, after simple acid treatment, it can be quickly transformed into a porous material with a significant surface area, making it highly desirable as a catalyst support [22]. A comparative study of NiW catalysts supported on acid-modified phonolite (A-Ph), foam zeolites, and alumina revealed that the NiW/A-Ph catalyst showed the highest activity for cracking and oxygen removal. Moreover, the A-Ph-supported catalyst resulted in the lowest carbonaceous deposits on the surface, which is significant as such deposits cause deactivation [23]. In this study, we use the above-mentioned NiW/A-Ph catalyst to coprocess VGO with different RSO ratios (0, 30, 50, 70, 90, and $100 \mathrm{wt}$. $)$ ) using a temperature of $420{ }^{\circ} \mathrm{C}, 18 \mathrm{MPa}$ of $\mathrm{H}_{2}$ with a $100 \mathrm{~L} / \mathrm{h}$ flow rate, and a weight hourly space velocity (WHSV) of $3 \mathrm{~h}^{-1}$. In particular, we focus on evaluation of its suitability in terms of product yield, oxygen removal pathways, and possible process-emissions savings.

\section{Materials and Methods}

\subsection{Feedstock Analysis}

As blending components, the commercial feedstocks VGO and RSO were used. RSO, food grade vegetable oil, was obtained at a local market from the company ARO. Except for when using pure VGO and RSO fractions, VGO was mixed with different shares of RSO to create a series of feedstock blends. The blends had an RSO content of 30\%, 50\%, 70\%, and $90 \%$, respectively. The feedstock characteristics are shown in Table 1. 
Table 1. Elemental composition of all utilized materials, including density and water content.

\begin{tabular}{|c|c|c|c|c|c|c|}
\hline Property & VGO & $30 \%$ RSO & $50 \%$ RSO & $70 \%$ RSO & $90 \%$ RSO & $100 \%$ RSO \\
\hline $\begin{array}{c}\text { Density }\left(15^{\circ} \mathrm{C}\right), \\
\mathrm{kg} / \mathrm{m}^{3}\end{array}$ & 905.1 & 905.9 & 908.8 & 913.8 & 918.5 & 919.8 \\
\hline Carbon, \% & 85.3 & 84.0 & 82.6 & 81.6 & 78.5 & 77.7 \\
\hline Hydrogen, \% & 12.7 & 12.5 & 12.5 & 12.4 & 12.0 & 12.0 \\
\hline Sulfur, ppm & 16,200 & 11,600 & 8607 & 3990 & 1714 & 1 \\
\hline Nitrogen, ppm & 493.0 & 394.0 & 340.0 & 216.0 & 104.0 & 1.3 \\
\hline Water, ppm & 119.7 & 157.6 & 221.6 & 243.2 & 276.9 & 289.3 \\
\hline Oxygen $1, \%$ & - & 2.28 & 3.98 & 5.56 & 9.30 & 10.27 \\
\hline
\end{tabular}

${ }^{1}$ Calculated by difference from the mass balance.

VGO, as an industrial stream, had a sulfur content of over $1.6 \%$, while RSO, as a vegetable oil, contained practically no sulfur (1.0 ppm). As expected, the oxygen and water contents increase together with the increase in the RSO share in the feedstock blend. RSO contains the oxygen, being its source in the elemental composition of the feedstock blends. Removing water from the raw materials is one of the main parameters for obtaining highquality biofuels, since in the future any free water content in biodiesel fuel will encourage biological growth in storage tanks, which could lead to corrosion of metals (iron, copper, and others) and the formation of sludge. Ultimately, this leads to clogged fuel filters and fuel lines, which in turn can damage a vehicle's fuel injection systems.

The boiling curves of all used fractions and mixtures, which were obtained using simulated distillation analysis, are shown in Figure 1.

For the pure RSO, simulated distillation (SIMDIS) results showed that the main products were mono-, di-, and triglycerides at boiling temperatures above $420^{\circ} \mathrm{C}$ by a very narrow distillation curve in the temperature range of $600-620^{\circ} \mathrm{C}$. No free fatty acids were found, as shown in Figure 1 (range of boiling temperatures: $340-420^{\circ} \mathrm{C}$ ). When the RSO was mixed with the VGO, the height of the distillation curve at temperatures over $600{ }^{\circ} \mathrm{C}$ varied depending on the respective contents of RSO and VGO in the blend.

\subsection{Support Material and Catalyst Preparation}

\subsubsection{Support Preparation-A-Phonolite (A-Ph)}

The material for the synthesis of the catalyst support, which is originally from the Czech Republic, was supplied by the company Keramost. Phonolite sand with a size range of $0.224-0.560 \mathrm{~mm}$ was sieved using Retsch AS300. Then, it was dried in an oven at $120^{\circ} \mathrm{C}$ overnight. The next step was leaching in $3 \mathrm{M}$ hydrochloric acid at $80^{\circ} \mathrm{C}$ for four hours (dealumination). The phonolite to acid ratio was 1:10 $(\mathrm{g} / \mathrm{mL})$. The obtained product was filtered, washed with demineralized water, and again dried in an oven at $120^{\circ} \mathrm{C}$ overnight. The prepared dried samples were then calcined at $500{ }^{\circ} \mathrm{C}$ for six hours with a $1{ }^{\circ} \mathrm{C} / \mathrm{min}$ temperature ramp in the air [23].

\subsubsection{Catalyst Preparation-5Ni10W/A-Phonolite (NiW/A-Ph)}

Acid-treated phonolite, using an aqueous solution of nickel nitrate and ammonium meta-tungstate, was impregnated. The support material impregnated with $5 \mathrm{wt} . \%$ nickel and $10 \mathrm{wt} . \%$ tungsten became a catalyst. The obtained catalyst was further calcined at $450{ }^{\circ} \mathrm{C}$ for six hours with a $1{ }^{\circ} \mathrm{C} / \mathrm{min}$ temperature ramp in the air. A detailed description of the step-by-step synthesis can be found in a recently published paper by Hidalgo et al. [24]. 


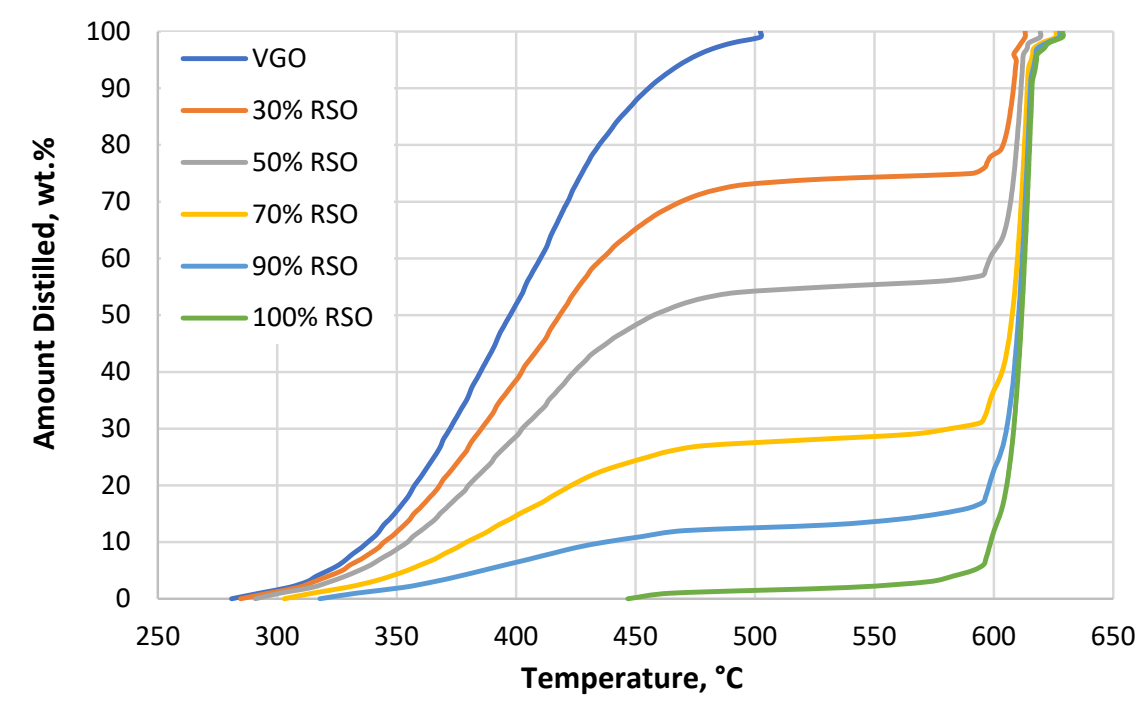

Figure 1. Simulated distillation (SIMDIS) curves of all the used feedstock materials. VGO is the feedstock without added RSO; 30\%, 50\%,70\%, and 90\% RSO are the blends containing $70 \%, 50 \%, 30 \%$, and $10 \%$ VGO, respectively; and 100\% RSO is pure rapeseed oil. The measurement was performed according to ASTM D7169 [25].

The suitability of the newly synthetized NiW/A-Ph catalyst was evaluated together with a commercially available NiW catalyst supported on amorphous silica-alumina (NiW/Comm.) by two parallel experiments. Experiments were conducted under the reaction conditions given for the commercial catalyst by the supplier $\left(420{ }^{\circ} \mathrm{C}, 18 \mathrm{MPa} \mathrm{H}_{2}\right.$, WHSV $=3 \mathrm{~h}^{-1}$ ), and using the same reactor setup.

\subsection{Experimental Setup and Catalytic Tests}

All experiments were carried out using a continuous-flow reactor system MaR 1101 (universal hydrogenation device) utilizing NiW catalysts based on two different support materials. The purpose of the experiments was the deoxygenation of RSO with the addition of VGO at various ratios. In total, two experiments were carried out with two catalytic systems on different supports (acid-modified phonolite and silica-alumina) under the same conditions and using the same methodology.

At the beginning, the reactor was loaded with $27 \mathrm{~g}$ of catalyst mixed with fine silicon carbide $(54 \mathrm{~mL})$ to improve the mass and heat transfer through the catalyst bed. Subsequently, the reactor was hermetically sealed and pressurized with a nitrogen pressure of 200 bar under an ambient temperature of $25{ }^{\circ} \mathrm{C}$ for a pressure test. Then, the reactor pressure was reduced to 45 bar using nitrogen at a selected $100 \mathrm{~L} / \mathrm{h}$ gas flow rate. Heating was then started to $350{ }^{\circ} \mathrm{C}$ with a heating rate of $30^{\circ} \mathrm{C} / \mathrm{h}$. After reaching the designated temperature, the gas was switched to hydrogen at a selected $25 \mathrm{~L} / \mathrm{h}$ flow rate and a pressure of 45 bar to flush out residual nitrogen. Subsequently, the hydrogen flow was increased to $100 \mathrm{~L} / \mathrm{h}$, and the injection of the sulfuring mixture (diesel $+2 \%$ DMDS) was begun. Simultaneous activation/sulfurization was carried out for $72 \mathrm{~h}$. The pressure was set to 90 bar, and the temperature increased to $420{ }^{\circ} \mathrm{C}$ with a $30{ }^{\circ} \mathrm{C} / \mathrm{h}$ gradient for $6 \mathrm{~h}$. After the drying phase, the operational gas was switched to hydrogen with a $100 \mathrm{~L} / \mathrm{h}$ flow rate and a pressure of 180 bar. To avoid an aggressive cracking reaction by a freshly activated catalyst, the temperature was reduced to $380^{\circ} \mathrm{C}$, and the feedstock injection at a flow rate of $81 \mathrm{~g} / \mathrm{h}$ was started (WHSV $=3 \mathrm{~h}^{-1}$ ). The temperature was then increased slowly to the desired $420{ }^{\circ} \mathrm{C}$ with a heating rate of $10^{\circ} \mathrm{C} / \mathrm{h}$. After reaching a reaction temperature of $420{ }^{\circ} \mathrm{C}$, the reactor was operated on pure vacuum gas oil for $72 \mathrm{~h}$ (stabilization). After the stabilization phase using VGO, the feedstock was immediately changed to a mixture of vacuum gas oil with different shares of rapeseed oil. The reactor operated on each blend for $48 \mathrm{~h}$. Liquid samples were collected every $4 \mathrm{~h}$ from the start of the feedstock injection, and the outcome 
gas was sampled every $24 \mathrm{~h}$. At the end of the experiment, the heating was turned off, and the operating gas was switched to nitrogen with a $100 \mathrm{~L} / \mathrm{h}$ flow rate and a pressure of 180 bar. After cooling to $200{ }^{\circ} \mathrm{C}$, a xylene flush was started using a $200 \mathrm{~g} / \mathrm{h}$ flow rate for $48 \mathrm{~h}$. After the cleaning, the pressure was reduced to 0 bar and the reactor dried under a $100 \mathrm{~L} / \mathrm{h}$ nitrogen flow rate for $6 \mathrm{~h}$. After drying, the gas flow was switched off, and after cooling to room temperature, the catalyst was recovered.

\subsection{Analyses of Materials and Products}

Gas and liquid products were analyzed using different techniques. Gaseous products were analyzed using Agilent's "Refinery Gas Analysis" method on an Agilent 7890A gas chromatograph with three parallel channels, which has two thermal conductivity detectors for $\mathrm{CO}, \mathrm{H}_{2}, \mathrm{~N}_{2}$, and $\mathrm{CO}_{2}$ determination, and a flame ionization detector for hydrocarbon detection.

The raw materials and the liquid products collected were analyzed by SIMDIS and compared to evaluate the suitability of both catalysts. Two main fraction yields were monitored in the liquid samples: jet fuel $\left(120-290^{\circ} \mathrm{C}\right)$ and diesel fraction $\left(180-360^{\circ} \mathrm{C}\right)$. The method of a high-temperature simulated distillation (ASTM D7169 [25]) performed by gas chromatography is used to determine the distribution of boiling points in the analyzed sample, depending on the distilled amount at the particular temperature. Injected samples with an initial boiling point above $35^{\circ} \mathrm{C}$ and an ending boiling point higher than $750{ }^{\circ} \mathrm{C}$ can be analyzed. Based on the analysis of the known hydrocarbon mixture, covering the sample distillation range and carried out under the same conditions as the sample, the boiling point time points are assigned from the calibration curve. Based on these data, the distribution of boiling points in the sample is determined. An Agilent 7890 HT/SIMDIS system was used. The column installed was DBHT-SIMD, $5 \mathrm{~m}, 0.53 \mathrm{~mm}, 0.15 \mu \mathrm{m}$. The density at $15^{\circ} \mathrm{C}$ was determined using a semi-hydrometer KYOTO DA-645 from Kyoto Electronics Manufacturing co. A FLASH 2000 Elemental Analyzer according to the ASTM D5291 [26] was used to determine the carbon and hydrogen contents of the samples. Also, the Trace SN Cube was used to determine the sulfur and nitrogen contents in products at micro scale according to ASTM D5453 [27] and ASTM D4629 [28].

To assess the efficiency of hydrocracking reactions, the selectivity, conversion, and product yield for the raw fractions of diesel and jet fuel were calculated using Equations (1)-(5) [29].

$$
\begin{aligned}
& \text { Diesel Conversion }=\frac{\text { Feed }>360^{\circ} \mathrm{C}-\text { Product }_{>360}{ }^{\circ} \mathrm{C}}{\text { Feed }_{>360}{ }^{\circ} \mathrm{C}} \\
& \text { Diesel Selectivity }=\frac{\text { Product }_{180-360{ }^{\circ} \mathrm{C}}-\text { Feed }_{180-360{ }^{\circ} \mathrm{C}}}{\text { Feed }_{>360}{ }^{\circ} \mathrm{C}-\text { Product }_{>360}{ }^{\circ} \mathrm{C}} \\
& \text { Jet Fuel Conversion }=\frac{\text { Feed }_{>290{ }^{\circ} \mathrm{C}-\text { Product }_{>290}{ }^{\circ} \mathrm{C}}}{\text { Feed }_{>290}{ }^{\circ} \mathrm{C}} \\
& \text { Jet Fuel Selectivity }=\frac{\text { Product }_{120-290{ }^{\circ} \mathrm{C}-\text { Feed }_{120-290}{ }^{\circ} \mathrm{C}}}{\text { Feed }_{>290}{ }^{\circ} \mathrm{C}-\text { Product }_{>290}{ }^{\circ} \mathrm{C}} \\
& \text { Fraction Yield }=\text { Fraction Conversion } * \text { Fraction Selectivity }
\end{aligned}
$$

\section{Results and Discussion}

The evaluation of results was focused on the catalyst's efficiency in terms of conversion, selectivity, and yields. The conversion, the same as the product yields, depended on the type of feed (RSO and/or VGO) and on the properties of the catalyst, the severity of the reaction, and the operating system used (reactor configuration, fluid dynamics, testing and analysis methods). Also, the raw liquid fuel fractions and the average gaseous product composition were controlled. Because two catalysts were used (commercial and research laboratory materials), the oxygen removal pathways of the two types of tests (using laboratory or commercial catalyst) are discussed. Both experiments were conducted under the reaction conditions defined by the supplier of the commercial NiW/silica-alumina 
catalyst. This research aimed to carry out an initial evaluation of the suitability of the novel $\mathrm{NiW}$ catalyst supported on A-Ph. Thus, before proceeding to the results and discussion, it must be mentioned that there is still room for and a need for optimization of the reaction conditions for the phonolite-based catalyst.

\subsection{Product Analysis}

\subsubsection{Liquid Product Quality}

Brief characteristics of the liquid products are presented in Table 2. The first significant difference between the liquids obtained by the utilization of both $\mathrm{NiW}$ catalysts is related to their density. As can be seen from Table 2 and Figure 2, NiW/Comm. produces a much lighter general liquid product compared with $\mathrm{NiW} / \mathrm{A}-\mathrm{Ph}$, which suggests more aggressive cracking. The lower density means lighter, smaller, or shorter-chain molecules instead of the larger molecules present in the feedstock.

Table 2. Characteristics of the liquid products: elemental composition, $\mathrm{H} / \mathrm{C}$ ratio, density, and water content of the products collected by processing each feedstock blend.

\begin{tabular}{|c|c|c|c|c|c|c|c|}
\hline \multicolumn{8}{|c|}{ NiW/A-Ph } \\
\hline Property & VGO-Start & $30 \%$ RSO & $50 \%$ RSO & $70 \%$ RSO & $90 \%$ RSO & $100 \%$ RSO & VGO-End \\
\hline $\begin{array}{c}\text { Density }\left(15^{\circ} \mathrm{C}\right) \\
\mathrm{kg} / \mathrm{m}^{3}\end{array}$ & 867.68 & 851.90 & 849.18 & 845.58 & 837.62 & 834.08 & 872.62 \\
\hline Carbon, $\%$ & 86.6 & 86.8 & 86.4 & 87.0 & 86.2 & 86.7 & 87.4 \\
\hline Hydrogen, \% & 13.4 & 13.4 & 13.4 & 13.4 & 13.5 & 13.6 & 13.0 \\
\hline H/C Ratio & 1.84 & 1.84 & 1.84 & 1.83 & 1.87 & 1.87 & 1.77 \\
\hline Sulfur, ppm & 343.33 & 94.15 & 133.50 & 253.50 & 153.50 & 82.50 & 1454.50 \\
\hline Nitrogen, ppm & 90.87 & 26.10 & 69.50 & 137.50 & 74.35 & 30.00 & 333.00 \\
\hline Water content, wt.\% & 0 & 0.2 & 2.5 & 4.1 & 6.2 & 8 & 0 \\
\hline \multicolumn{8}{|c|}{ NiW/Comm. } \\
\hline $\begin{array}{c}\text { Density }\left(15^{\circ} \mathrm{C}\right), \\
\mathrm{kg} / \mathrm{m}^{3}\end{array}$ & 834.90 & 814.53 & 814.39 & 815.00 & 812.62 & 809.59 & 849.97 \\
\hline Carbon, \% & 85.6 & 85.5 & 86.0 & 85.9 & 85.6 & 85.6 & 86.8 \\
\hline Hydrogen, \% & 14.0 & 14.5 & 14.4 & 14.2 & 14.6 & 14.2 & 13.3 \\
\hline H/C Ratio & 1.95 & 2.01 & 2.00 & 1.96 & 2.03 & 1.98 & 1.83 \\
\hline Sulfur, ppm & 10.39 & 18.10 & 45.90 & 28.10 & 16.00 & 2.51 & 19.95 \\
\hline Nitrogen, ppm & 1.03 & 0.87 & 0.74 & 0.37 & 0.38 & 0.17 & 1.17 \\
\hline Water content, wt.\% & 0 & 1.1 & 3.9 & 5.8 & 7.9 & 10.1 & 0.2 \\
\hline
\end{tabular}

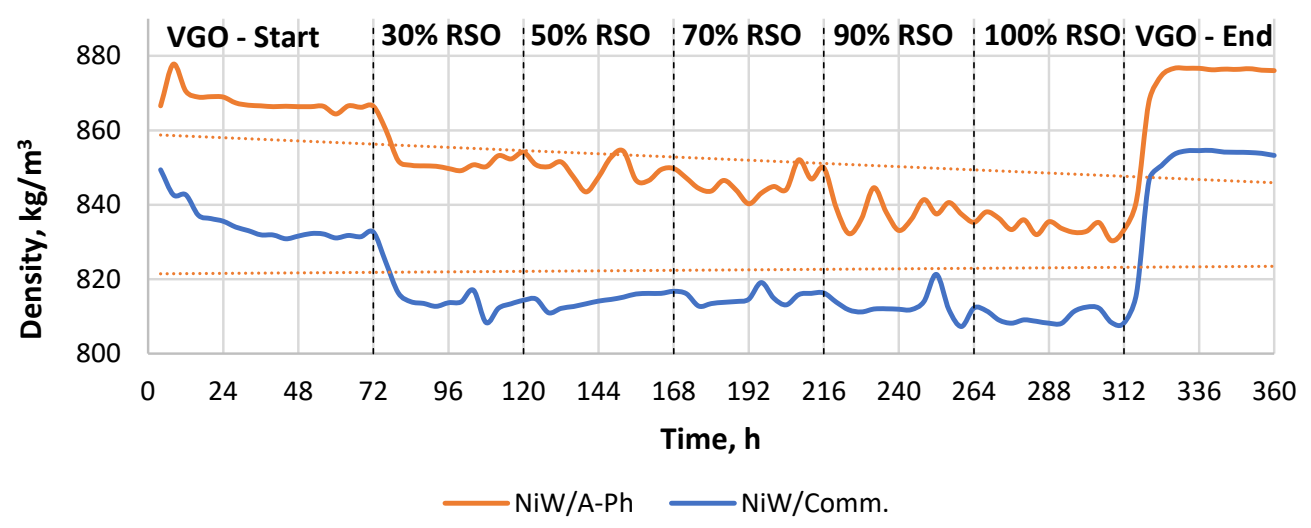

Figure 2. The density of the products throughout the experiment performed using two catalysts (NiW/A-Ph, NiW/Comm.). The experiment started by processing pure VGO, and then there were five feedstock blend changes using 30\%,50\%,70\%, 90\%, and 100\% RSO, respectively. 
Surprisingly, there are two similar visible trends in terms of the density of liquid products. The density of the liquid product gained from RSO-containing feedstock processed over NiW/Comm. decreases very slightly, with the mean value in the range of $809-815 \mathrm{~kg} / \mathrm{m}^{3}$. Meanwhile, the density of the liquid product produced from the RSOcontaining material processed over the NiW/A-Ph catalyst significantly decreased with increasing RSO content over time. In terms of fuel production, however, products gained by $90-100 \%$ RSO processing over the NiW/A-Ph catalyst under the tested conditions had a density matching the restrictions of the European EN590 standard for diesel fuel, being in the range of $820-845 \mathrm{~kg} / \mathrm{m}^{3}$ [30].

The density of the products increased when more RSO was included in the feedstock mixture. However, the $\mathrm{H} / \mathrm{C}$ ratio was lower, indicating a lower content of saturated linear paraffins. For the commercial catalyst, the VGO final test led to a product with a H/C ratio of 1.83, which was a lower number compared with 1.95 at the start of the reaction, indicating a deactivation of the catalyst. For the phonolite-type catalyst, the trend was similar but with lower $\mathrm{H} / \mathrm{C}$ ratio values, indicating a lower hydrogenation activity during the reaction compared with the reaction using the commercial catalyst.

As can be seen in Table 2, the sulfur and nitrogen removal was much more efficient when the commercial catalyst was used. The heteroatom content of the liquid products obtained by the commercial catalyst was in the range of $0-50 \mathrm{ppm}$ for sulfur and $0.0-1.05 \mathrm{ppm}$ for nitrogen, respectively (Table 2, Figure 3). In the case of the research catalyst NiW/A-Ph, the average heteroatom content for the liquid products gained while processing RSOcontaining blends was in the range of $80-255 \mathrm{ppm}$ for sulfur and $25-140 \mathrm{ppm}$ for nitrogen (Table 2, Figure 4).

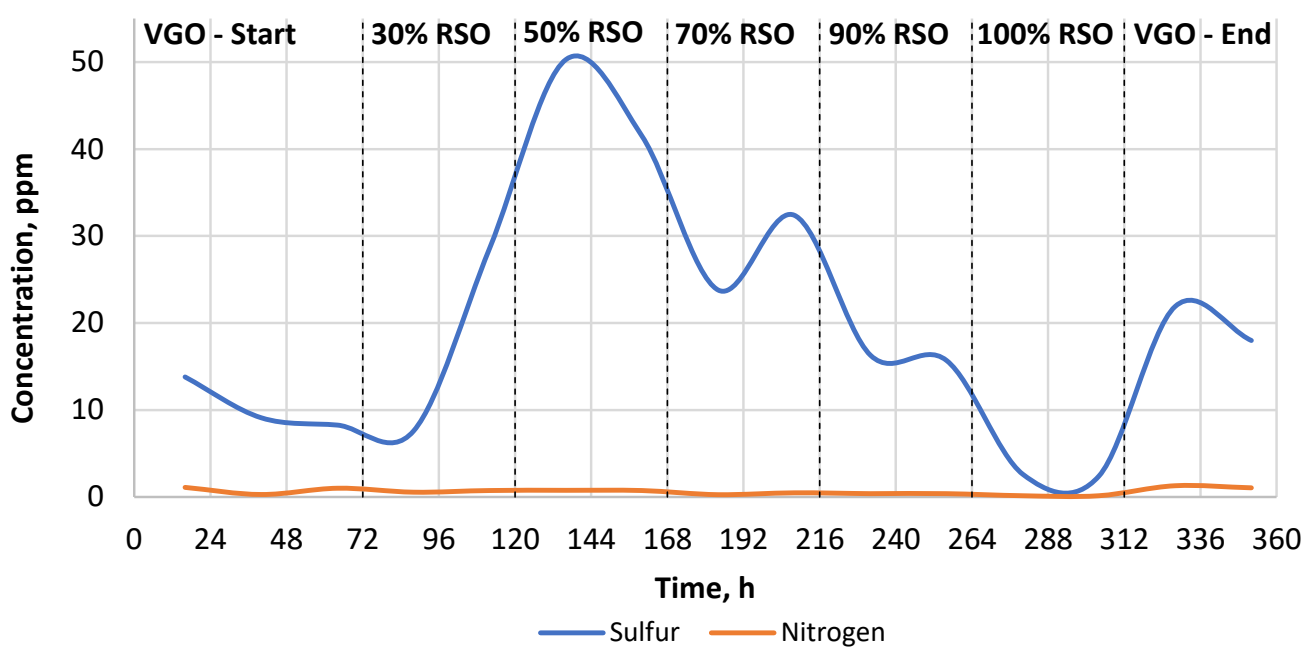

Figure 3. The change in the heteroatom content $(S, N)$ in the liquid products throughout the experiment carried out using the $\mathrm{NiW} /$ Comm. catalyst.

As can be seen in Figure 4, after the catalyst started processing RSO-containing feed, the heteroatom removal continuously decreased with the higher RSO addition in the range of 30-90\% RSO. This is usually related to catalyst deactivation due to RSO addition (coking, sulfur leaching, etc.). Lower sulfur content results were gained when pure RSO was processed, which is surely related to the almost zero sulfur and nitrogen contents in the RSO composition. On the contrary, when processing pure VGO, the content of heteroatoms was quite high, which is due to the fact that the industrial raw material of VGO contains a sufficiently high content of sulfur. Nevertheless, the increased sulfur content for the products obtained from pure RSO processing suggests a sulfur leaching from the catalyst bed to the liquid products. In addition, as mentioned, this result is probably related to the relatively short time ( $48 \mathrm{~h}$ ) of processing for $100 \%$ RSO. The sulfur leaching, suggested by the increased sulfur content in liquid products collected from RSO processing, would surely lead to severe catalyst deactivation over time. 


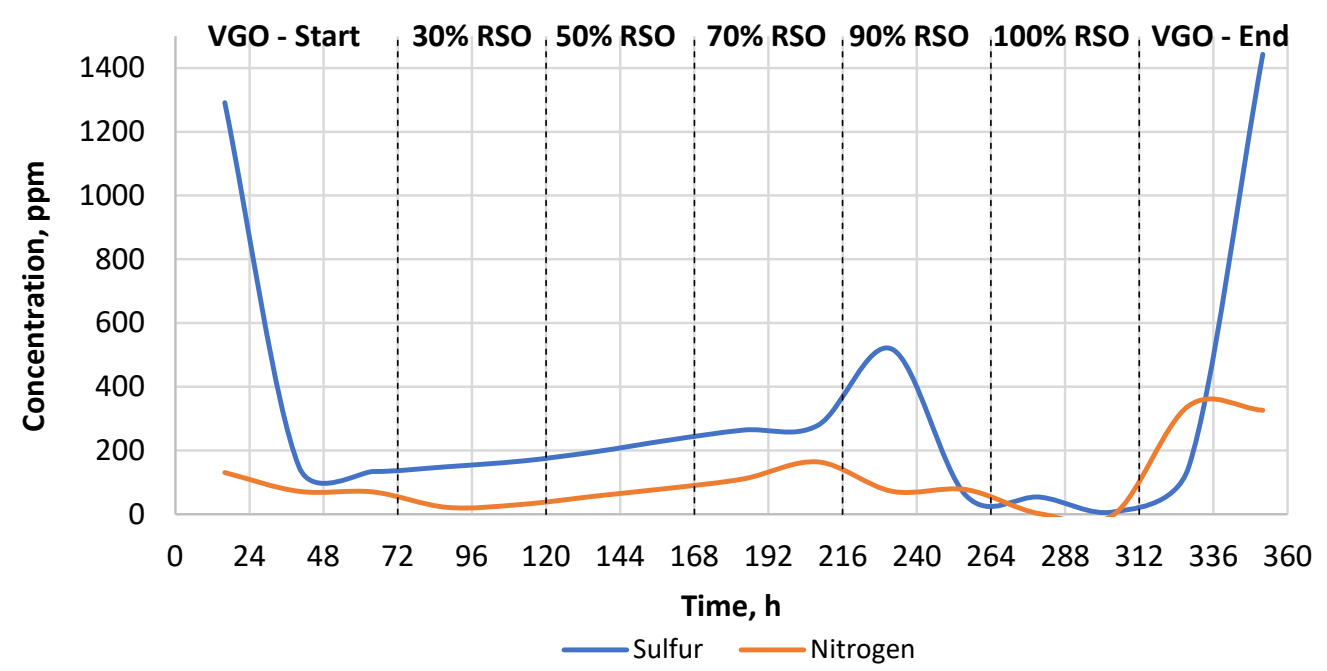

Figure 4. The change in the heteroatom content $(\mathrm{S}, \mathrm{N})$ in the liquid products throughout the experiment carried out using the NiW/A-Ph catalyst.

Sulfur removal and nitrogen removal were very efficient when the commercial catalyst was used. Nevertheless, even in this case, the catalyst needed to stabilize for a minimum of $24 \mathrm{~h}$ after the feedstock blend change, which is presented in Figure 3.

The most significant finding, however, is related to the possible hydrogen savings, more concretely the oxygen removal pathways. As can be seen in Table 2, the water content observed in the liquid products is significantly higher for the commercial NiW catalyst. This suggests a more favorable hydrodeoxygenation pathway of oxygen removal, which produces water as an effect of the reaction of oxygen and hydrogen. This seems to be proven by the lower hydrogen content in the outcome gas using the commercial catalyst (Figure 5). Besides the possibility of a water-gas shift reaction, which is possibly taking place in all the experiments carried out, there is still a visible difference in the $\mathrm{CO}_{2}$ and $\mathrm{H}_{2} \mathrm{O}$ produced by NiW/Comm. in comparison with NiW/A-Ph. The expected water content is higher when RSO is used, due to the deoxygenation of the triglycerides.

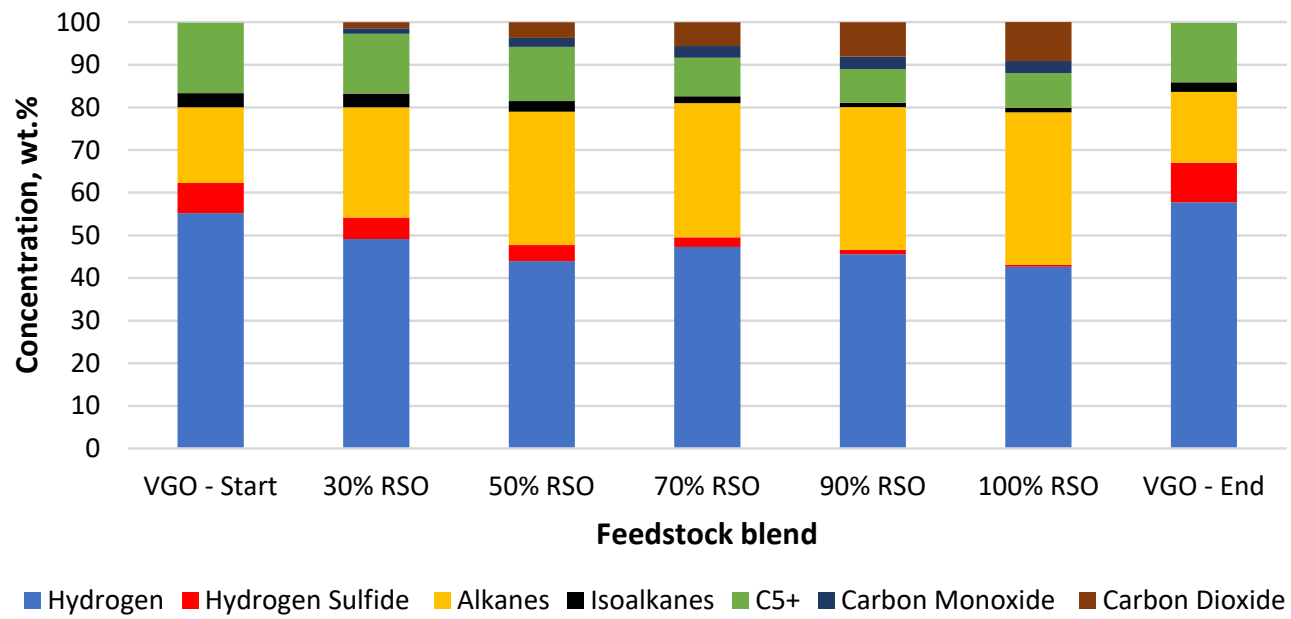

Figure 5. Composition of the main gaseous products collected for each feedstock blend processed using the $\mathrm{NiW} /$ Comm. catalyst.

\subsubsection{Gaseous Product Quality}

$\mathrm{NiW}$ catalysts were used in this research to possibly improve the hydrogen savings by enhanced decarbonylation and decarboxylation pathways of oxygen removal, produc- 
ing $\mathrm{CO}$ and $\mathrm{CO}_{2}$, respectively. As can be seen in Figures 5 and 6, decarboxylation and decarbonylation occurred for both tested catalysts.

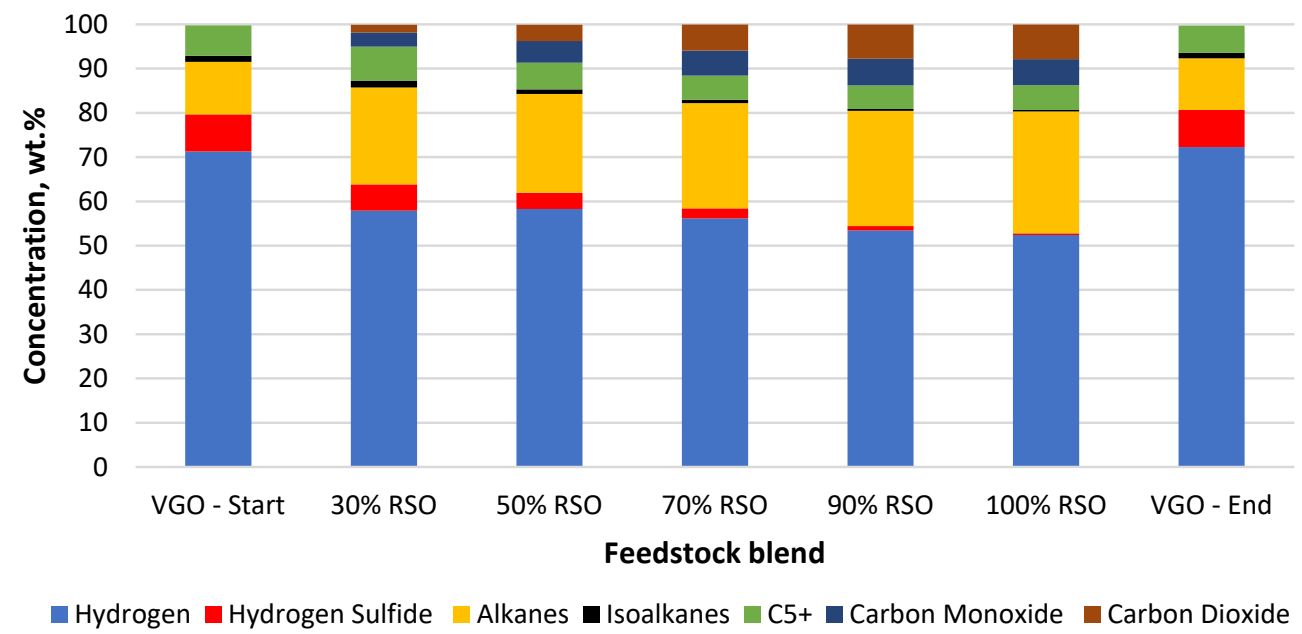

Figure 6. Composition of the main gaseous products collected for each feedstock blend processed using the NiW/A-Ph catalyst.

In the case of the water formation (deoxygenation) with the NiW/A-Ph catalyst, decarbonylation was a more favorable way of oxygen removal (Table 2, Figure 6). The composition of the gaseous product gained by using NiW/ A-Ph seems to be less harmful to the environment, with less $\mathrm{CO}_{2}, \mathrm{H}_{2} \mathrm{~S}$, and cracking gases and a higher level of hydrocarbons compared with the gas produced by NiW/Comm.

In terms of cleaner fuel production and possible hydrogen savings, the best way for oxygen removal seems to be decarbonylation, producing $\mathrm{CO}$ and $\mathrm{H}_{2} \mathrm{O}$ as products. Meanwhile, $\mathrm{CO}_{2}$ is a problematic emission gas, whereas $\mathrm{CO}$ can be separated from the outcome gas and be further processed to produce fuels or other chemicals. In light of the abovementioned benefits, $\mathrm{NiW} / \mathrm{A}-\mathrm{Ph}$ looks very promising in comparison with NiW/Comm. The NiW/Comm. catalyst prefers hydrodeoxygenation and decarboxylation reactions, giving significantly more water and almost two times more $\mathrm{CO}_{2}$ compared with $\mathrm{NiW} / \mathrm{A}-\mathrm{Ph}$ (Table 2, Figure 5).

\subsection{Conversion, Selectivity, and Yield for Raw Fuel Fractions}

The conversion and selectivity for diesel and jet fuel fractions by using the NiW catalysts is presented in Table 3. Generally, NiW/Comm. tests led to a better overall result in terms of conversion, selectivity, and yield compared with the tests performed using NiW/A-Ph. This difference in activity was found for these specific reaction conditions. Nevertheless, both of the catalysts were able to process the VGO and RSO, as well as their blends.

In the case of conversion and yield, the greatest difference between the tested catalysts can be observed with pure VGO processing. The use of a pure industrial fraction of VGO led to a lower efficiency in obtaining diesel and jet fuel fractions with the lowest overall conversion of $33.6 \%$ and yield of $11.4 \%$ (jet fuel fraction). Taking into account that the VGO presented different contents of hydrocarbons, sulfur, and nitrogen compounds, a change in the general conversion was expected. Similar results were obtained by Chen et al. [31], where an $80 / 20$ heavy vacuum gas oil (HVGO)/canola oil blend was found to have product yields of $36-40 \%$, while pure HVGO had the lowest. Thus, they concluded that canola oil is easier to crack than HVGO.

The RSO contains triglycerides, which react to produce free fatty acids by $\beta$-elimination and cracking reactions. Subsequent fatty acid deoxygenation proceeds via decarboxylation/decarbonylation and produces hydrocarbons, which are then hydrocracked into shorter molecules [32]. Furthermore, the RSO generates (after only the deoxygenation pathway reaction) mainly $\mathrm{C} 17$ compounds, which are then hydrocracked into shorter 
hydrocarbons. This reaction pathway directly affects the hydrocracking reaction of VGO, which contains hydrocarbons from $\mathrm{C} 16$ to $\mathrm{C} 31$ (boiling range of $300-450{ }^{\circ} \mathrm{C}$ ). Therefore, the addition of RSO increases the yield of jet fuel and diesel fractions, due to its initial content generating mainly C17 hydrocarbons. Moreover, Rana et al. [16], when studying the co-processing of used vegetable oil and light atmospheric gas oil, found that increasing the content of used oil in the feed resulted in higher product yields. Thus, the final product consisted mainly of diesel range hydrocarbons ( $60-90 \%$ yield) and a small amount of jet fuel range hydrocarbons (10-35\% yield).

The differences between catalyst efficiencies decrease over time, together with the increase in the RSO content in the feedstock. The highest RSO share in the feedstock blend also led to the highest overall raw fuel fraction yields, which is graphically presented in Figures 7 and 8 .

Table 3. Conversion, selectivity, and yield for raw fuel fractions (diesel, jet fuel) produced using both tested NiW catalysts (NiW/A-Ph, NiW/Comm.).

\begin{tabular}{|c|c|c|c|c|c|c|}
\hline \multicolumn{7}{|c|}{ NiW/A-Ph } \\
\hline & \multicolumn{3}{|c|}{ Diesel Fraction } & \multicolumn{3}{|c|}{ Jet Fuel Fraction } \\
\hline & Conversion (\%) & Selectivity (\%) & Yield (\%) & Conversion (\%) & Selectivity (\%) & Yield (\%) \\
\hline VGO & 33.6 & 62.3 & 20.9 & 19.7 & 58.0 & 11.4 \\
\hline $30 \% \mathrm{RSO}$ & 52.7 & 57.4 & 30.2 & 31.7 & 52.3 & 16.6 \\
\hline $50 \%$ RSO & 59.8 & 51.8 & 30.9 & 40.1 & 48.0 & 19.2 \\
\hline $70 \% \mathrm{RSO}$ & 61.6 & 58.7 & 36.1 & 40.0 & 53.4 & 21.3 \\
\hline $90 \%$ RSO & 66.1 & 57.0 & 37.7 & 45.8 & 57.4 & 26.3 \\
\hline $100 \%$ RSO & 68.0 & 56.2 & 38.2 & 48.9 & 59.0 & 28.8 \\
\hline \multicolumn{7}{|c|}{ NiW/Comm. } \\
\hline & \multicolumn{3}{|c|}{ Diesel fraction } & \multicolumn{3}{|c|}{ Jet Fuel fraction } \\
\hline & Conversion (\%) & Selectivity (\%) & Yield (\%) & Conversion (\%) & Selectivity (\%) & Yield (\%) \\
\hline VGO & 57.1 & 58.9 & 33.6 & 40.1 & 66.1 & 26.5 \\
\hline $30 \%$ RSO & 75.5 & 55.9 & 42.2 & 51.2 & 60.9 & 31.2 \\
\hline $50 \%$ RSO & 75.7 & 60.9 & 46.1 & 51.0 & 67.8 & 34.5 \\
\hline $70 \% \mathrm{RSO}$ & 77.3 & 59.4 & 45.9 & 52.9 & 62.9 & 33.2 \\
\hline $90 \%$ RSO & 78.5 & 60.0 & 47.1 & 54.2 & 64.4 & 34.9 \\
\hline $100 \%$ RSO & 80.2 & 59.8 & 47.9 & 56.8 & 65.3 & 37.1 \\
\hline
\end{tabular}

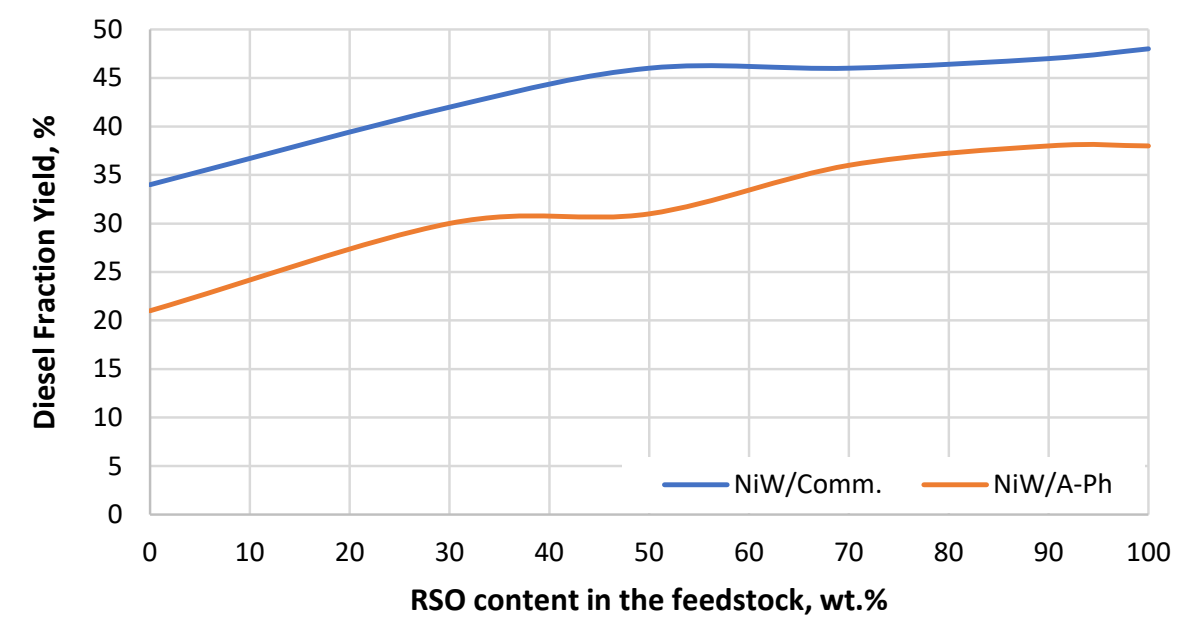

Figure 7. Diesel fraction yield gained throughout the experiment using both tested NiW catalysts (NiW/A-Ph, NiW/Comm.) depending on the RSO content in the processed feedstock blend. 


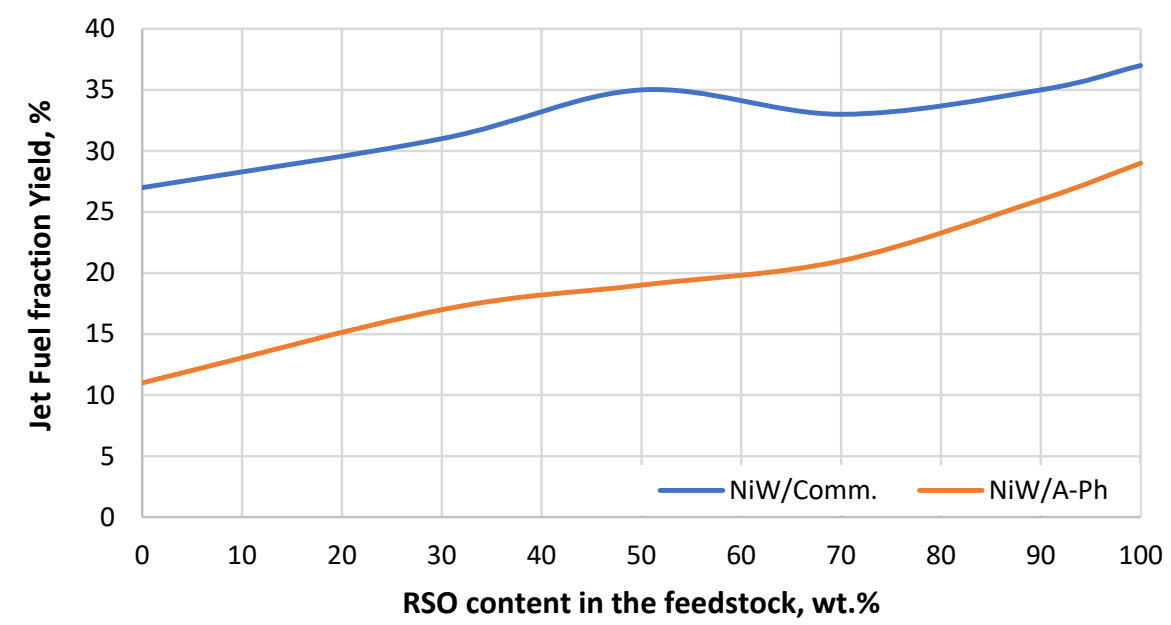

Figure 8. Jet fuel fraction yield gained throughout the experiment using both tested NiW catalysts (NiW/A-Ph, NiW/Comm.) depending on the RSO content in the processed feedstock blend.

Regarding diesel fraction yield (Figure 7), the differences between the two tested NiW catalysts were rather constant throughout the experiment. Both catalysts showed the best results when pure RSO was the feedstock. This result could be related to the previous obtainment of linear paraffins by HDO, and their subsequent hydrocracking to diesel, jet fuel, and other products. The VGO contains not only linear paraffins but also other types of hydrocarbons such as aromatic and naphtenes. In addition, the relatively short time of reaction $(48 \mathrm{~h})$, even when having a feedstock with sufficient sulfur content, was not enough to cause loss of efficiency at the active sites (metal sulfides and loss of sulfur). It would be expected to see severe deactivation due to sulfur leaching when processing RSO for a longer time.

Phonolite is a novel potential raw material for use as a catalyst support. With its acid modification, the phonolite acquires porous properties with a significant surface area, becoming a cost-effective support material for catalyst preparation. Furthermore, the novel application of phonolite as a new type of catalyst gives information about the effects of adding RSO on VGO processing. The experiment is aimed at future expansion of phonolite application for further use in refinery operations, specifically for the co-processing of feedstocks with a partial bio-origin. Therefore, this information is useful not only for researchers but also for refineries.

It also needs to be mentioned that our work has some uniqueness in comparison with the existing literature. There was no information about the use of phonolite-based catalysts for processing bio-derived materials from other publications. Thus, this indicates the novelty of our work.

\section{Conclusions}

Two catalysts (NiW/Comm. and NiW/A-Ph) were tested in the hydrocracking reaction of RSO and/or VGO feedstocks. Both catalysts were active in the hydrocracking of the feedstock mixtures, with the commercial catalyst being the most active in the production of diesel and jet fuels. Moreover, tests on the NiW/Comm. catalyst led to better overall results in terms of conversion, selectivity, and yield compared with tests performed using $\mathrm{NiW} / \mathrm{A}-\mathrm{Ph}$. However, the composition of the gaseous product obtained by NiW/A-Ph appears to be less harmful to the environment as it contained less $\mathrm{CO}_{2}, \mathrm{H}_{2} \mathrm{~S}$, and cracking gases and more hydrocarbons than the gas produced by the commercial catalyst. The $\mathrm{NiW} /$ Comm. catalyst preferred hydrodeoxygenation and decarboxylation reactions, producing significantly more water and almost double the amount of $\mathrm{CO}_{2} \mathrm{Compared}$ with $\mathrm{NiW} / \mathrm{A}-\mathrm{Ph}$. The best jet fuel and diesel fraction yields were found for the tests using pure RSO. This study suggests the initial suitability of the NiW/A-Ph catalyst for processing feedstocks with an increased oxygen content, showing a comparable result to a commer- 
cial catalyst. Even despite the operation in possibly non-optimized reaction conditions, the phonolite-based catalyst showed a comparable result to the NiW/Comm. catalyst. Moreover, the NiW/A-Ph catalyst showed a better performance regarding possible hydrogen and emission savings, which is significant for cleaner fuel production in the future. This study highlights the benefit of further optimization of the operating conditions for phonolite-based catalysts. To conclude, the NiW/A-Ph catalyst is a promising candidate to be utilized for the processing of oxygenated feedstocks with bio-origin.

Author Contributions: Conceptualization, J.F. and J.M.H.-H.; methodology, J.F., Z.T. and H.D.P.C.; validation, J.F., J.M.H.-H., H.D.P.C. and Z.T.; data curation, J.F., Z.T. and J.M.H.-H.; visualization and writing-original draft preparation, J.F. and N.S.; funding acquisition, J.F.; project administration, J.F.; and writing-review and editing, J.F., N.S., J.M.H.-H. and H.D.P.C. All authors have read and agreed to the published version of the manuscript."

Funding: This publication is a result of a project that was funded by Ministry of Industry and Trade of the Czech Republic, with institutional support for long-term conceptual development of research organization. The result was achieved using the infrastructure included in the project Efficient Use of Energy Resources Using Catalytic Processes (LM2018119), which has been financially supported by MEYS within the targeted support of large infrastructures.

Institutional Review Board Statement: Not applicable.

Informed Consent Statement: Not applicable.

Data Availability Statement: Not applicable.

Conflicts of Interest: The authors declare no conflict of interest.

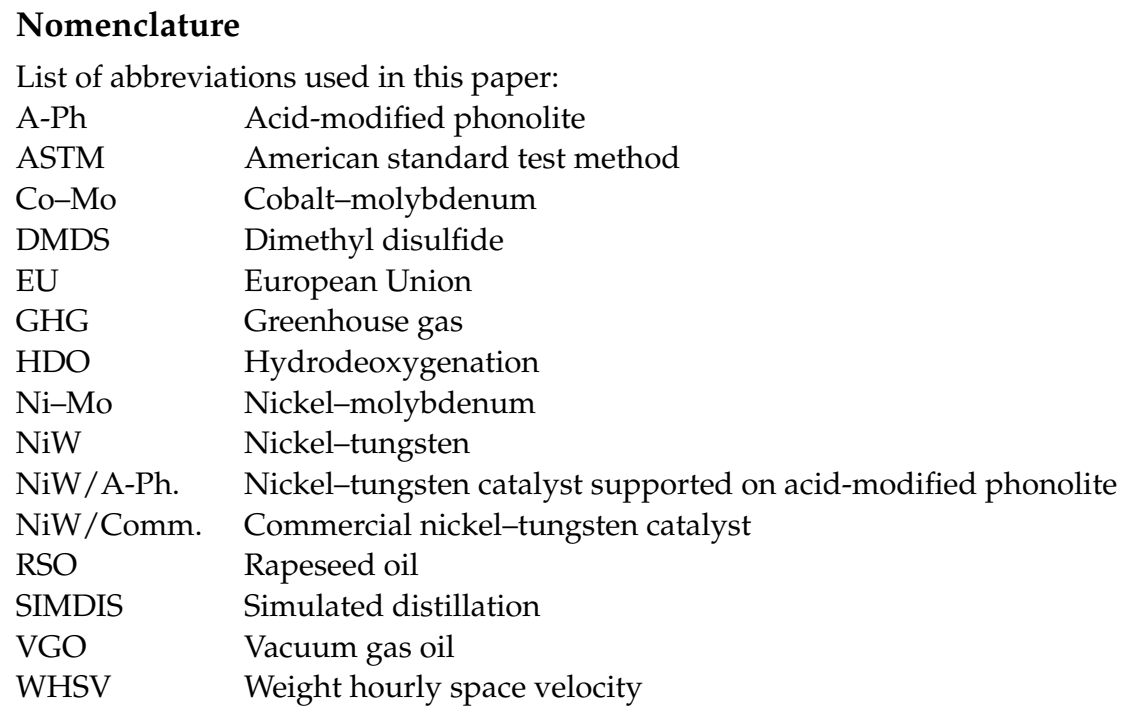

\section{References}

1. European Environment Agency (EEA). National Emissions Reported to the UNFCCC and to the EU Greenhouse Gas Monitoring Mechanism. 2019. Available online: https:/ / www.eea.europa.eu/data-and-maps/indicators/transport-emissions-ofgreenhouse-gases-7/assessment (accessed on 16 January 2020).

2. Aatola, H.; Larmi, M.; Sarjovaara, T.; Mikkonen, S. Hydrotreated Vegetable Oil (HVO) as a Renewable Diesel Fuel: Trade-off between NOx, Particulate Emission, and Fuel Consumption of a Heavy Duty Engine. SAE Int. J. Engines 2009, 1, $1251-1262$. [CrossRef]

3. Kalnes, T.; Marker, T.; Shonnard, D. Green diesel: A second generation biofuel. Int. J. Chem. React. Eng. 2007, 5, 5. [CrossRef]

4. ConocoPhillips Begins Production of Renewable Diesel, Biodiesel Magazine. 2007. Available online: http://www. biodieselmagazine.com/articles/1481/conocophillips-begins-production-of-renewable-diesel (accessed on 18 January 2020).

5. Hancsok, J.; Krar, M.; Kasza, T.; Kovacs, S.; Toth, C.; Varga, Z. Ivestigation of hydrotreating of vegetable gas-oil mixtures. J. Environ. Sci. Eng. 2011, 5, 500-507.

6. Bezergianni, S.; Dimitriadis, A.; Kikhtyanin, O.; Kubička, D. Refinery co-processing of renewable feeds. Prog. Energy Combust. Sci. 2018, 68, 29-64. [CrossRef] 
7. Horáček, J.; Akhmetzyanova, U.; Skuhrovcová, L.; Tišler, Z.; de Carmona, H. Alumina-supported MoNx, MoCx and MoPx catalysts for the hydrotreatment of rapeseed oil. Appl. Catal. B Environ. 2020, 263, 118328. [CrossRef]

8. Melero, J.A.; Clavero, M.M.; Calleja, G.; Garciía, A.; Miravalles, R.; Galindo, T. Production of Biofuels via the Catalytic Cracking of Mixtures of Crude Vegetable Oils and Nonedible Animal Fats with Vacuum Gas Oil. Energy Fuels 2010, 24, 707-717. [CrossRef]

9. Doronin, V.P.; Potapenko, O.V.; Lipin, P.V.; Sorokina, T.P.; Buluchevskaya, L.A. Catalytic cracking of vegetable oils for production of high-octane gasoline and petrochemical feedstock. Pet. Chem. 2012, 52, 392-400. [CrossRef]

10. Carmona, H.D.; Akhmetzyanova, U.; Tišler, Z.; Vondrová, P. Hydrotreating atmospheric gasoil and co-processing with rapeseed oil using supported Ni-Mo and Co-Mo carbide catalysts. Fuel 2020, 268, 117363. [CrossRef]

11. Ng, S.H.; Heshka, N.E.; Lay, C.; Little, E.; Zheng, Y.; Wei, Q.; Ding, F. FCC coprocessing oil sands heavy gas oil and canola oil. 2. Gasoline hydrocarbon type analysis. Green Energy Environ. 2018, 3, 286-301. [CrossRef]

12. Abbot, J. The influence of olefins on cracking reactions of saturated hydrocarbons. J. Catal. 1990, 126, 684-688. [CrossRef]

13. Beirnaert, H.C.; Alleman, J.R.; Marin, G.B. A Fundamental Kinetic Model for the Catalytic Cracking of Alkanes on a USY Zeolite in the Presence of Coke Formation. Ind. Eng. Chem. Res. 2001, 40, 1337-1347. [CrossRef]

14. Siger, A.; Gawrysiak-Witulska, M.; Bartkowiak-Broda, I. Antioxidant (Tocopherol and Canolol) Content in Rapeseed Oil Obtained from Roasted Yellow-Seeded Brassica napus. J. Am. Oil Chem. Soc. 2017, 94, 37-46. [CrossRef] [PubMed]

15. Toth, C.; Baladicz, P.; Hancsok, J. Production of bio gas oil containing diesel fuel with upgraded cold flow properties by coprocessing. In Proceedings of the 15th International Conference on Process Integration, Modelling and Optimization for Energy Saving and Pollution Reduction, Prague, Czech Republic, 25-29 August 2012; pp. 613-618.

16. Rana, B.S.; Kumar, R.; Tiwari, R.; Kumar, R.; Joshi, R.K.; Garg, M.O.; Sinha, A.K. Transportation fuels from co-processing of waste vegetable oil and gas oil mixtures. Biomass Bioenergy 2013, 56, 43-52. [CrossRef]

17. Mikulec, J.; Cvengroš, J.; Joríková, L'.; Banič, M.; Kleinová, A. Second generation diesel fuel from renewable sources. J. Clean. Prod. 2010, 18, 917-926. [CrossRef]

18. Al-Sabawi, M.; Chen, J.; Ng, S. Fluid Catalytic Cracking of Biomass-Derived Oils and Their Blends with Petroleum Feedstocks: A Review. Energy Fuels 2012, 26, 5355-5372. [CrossRef]

19. Biswas, J.; Maxwell, I.E. Recent process- and catalyst-related developments in fluid catalytic cracking. Appl. Catal. 1990, 63, 197-258. [CrossRef]

20. Primo, A.; Garcia, H. Zeolites as catalysts in oil refining. Chem. Soc. Rev. 2014, 43, 7548-7561. [CrossRef]

21. Keramost a.s. Czech Republic (2018) Phonolite Supplied by the Company Keramost, Most. Available online: http://www. keramost.cz/en/products/- / phonolite (accessed on 18 January 2020).

22. Strejcová, K.; Tišler, Z.; Svobodová, E.; Velvarská, R. Characterization of Modified Natural Minerals and Rocks for Possible Adsorption and Catalytic Use. Molecules 2020, 25, 4989. [CrossRef]

23. Herrador, J.M.; Tišler, Z.; Vráblík, A.; Velvarská, R.; Lederer, J. Acid-modified phonolite and foamed zeolite as supports for NiW catalysts for deoxygenation of waste rendering fat. React. Kinet. Mech. Catal. 2018, 126, 773-793.

24. Herrador, J.M.; Fratczak, J.; Tišler, Z.; de Carmona, H.; Velvarská, R. Oxalic Acid as a Hydrogen Donor for the Hydrodesulfurization of Gas Oil and Deoxygenation of Rapeseed Oil Using Phonolite-Based Catalysts. Molecules 2020, 25, 3732. [CrossRef] [PubMed]

25. ASTM International-ASTM D7169. Standard Test Method for Boiling Point Distribution of Samples with Residues Such as Crude Oils and Atmospheric and Vacuum Residues by High Temperature Gas Chromatography; ASTM International: West Conshohocken, PA, USA, 2016.

26. ASTM International-ASTM D5291. Standard Test Methods for Instrumental Determination of Carbon, Hydrogen, and Nitrogen in Petroleum Products and Lubricants; ASTM International: West Conshohocken, PA, USA, 2016.

27. ASTM International-ASTM D5453. Standard Test Method for Determination of Total Sulfur in Light Hydrocarbons, Spark Ignition Engine Fuel, Diesel Engine Fuel, and Engine Oil by Ultraviolet Fluorescence; ASTM International: West Conshohocken, PA, USA, 2016.

28. ASTM International-ASTM D4629. Standard Test Method for Trace Nitrogen in Liquid Hydrocarbons by Syringe/Inlet Oxidative Combustion and Chemiluminescence Detection; ASTM International: West Conshohocken, PA, USA, 2016.

29. Bezergianni, S.; Dimitriadis, A.; Kalogianni, A.; Pilavachi, P.A. Hydrotreating of waste cooking oil for biodiesel production. Part I: Effect of temperature on product yields and heteroatom removal. Bioresour. Technol. 2010, 101, 6651-6656. [CrossRef] [PubMed]

30. De Normalisation, C.E. Automotive fuels-Diesel-Requirements and test methods. SS-EN 2014, 590, 2013.

31. Chen, J.; Farooqi, H.; Fairbridge, C. Experimental Study on Co-hydroprocessing Canola Oil and Heavy Vacuum Gas Oil Blends. Energy Fuels 2013, 27, 3306-3315. [CrossRef]

32. Morgan, T.; Santillan-Jimenez, E.; Harman-Ware, A.E.; Ji, Y.; Grubb, D.; Crocker, M. Catalytic deoxygenation of triglycerides to hydrocarbons over supported nickel catalysts. Chem. Eng. J. 2012, 189, 346-355. [CrossRef] 